\title{
Tsafon
}

Revue d'études juives du Nord

$80 \mid 2020$

Varia

\section{Claude Vigée (1921-2020)}

Ce chant donné en partage

\section{Andrée Lerousseau}

\section{CpenEdition}

\section{Journals}

Édition électronique

URL : https://journals.openedition.org/tsafon/3435

DOI : $10.4000 /$ tsafon.3435

ISSN : 2609-6420

Éditeur

Association Jean-Marie Delmaire

\section{Édition imprimée}

Date de publication : 1 décembre 2020

Pagination : 163-168

ISSN : 1149-6630

\section{Référence électronique}

Andrée Lerousseau, «Claude Vigée (1921-2020)», Tsafon [En ligne], 80 | 2020, mis en ligne le 01 décembre 2020, consulté le 24 juin 2021. URL : http://journals.openedition.org/tsafon/3435 ; DOI : https://doi.org/10.4000/tsafon.3435 


\title{
Hommage
}

\section{Claude Vigée (1921-2020)}

\author{
Ce chant donné en partage
}

\author{
Andrée Lerousseau* \\ Saltimbanque aux entrailles tordues par la terreur, \\ j'avance à contretemps \\ j'erre à contre-nations, \\ m'amusant, les narguant, exultant sur le vide ${ }^{1}$
}

Né le 3 janvier 1921 en Alsace, à Bischwiller, Claude-André Strauss, qui deviendra Claude Vigée, est décédé à Paris la veille de Souccoth 5781, le 2 octobre 2020. Réfugié à Toulouse, il avait vu sa vie basculer le 15 octobre 1940, date de la promulgation du décret ignominieux sur le statut des Juifs de France : «jamais je n'oublierai cet instant-là, qui achevait, à dix-neuf ans, de diviser ma vie en deux temps irréconciliables : celui de la confiance naïve et du primesaut; celui du doute et de l'abandon $»^{2}$. Dans la vieille synagogue de la rue Palaprat, le jeune homme renoue avec ses racines et entre en résistance au sein de l'Action juive. L'année même où l'Allemagne décrète la «solution finale ", il publie son premier poème sous le pseudonyme de Claude Vigée dans la Revue Poésie 42 de Pierre Seghers, inscrivant dans ce nom qu'il s'était choisi, et qui résonne comme un défi lancé à l'ennemi, la vocation même du poète et du Juif comme « passeur du vivant $»^{3}$ :

\footnotetext{
${ }^{*}$ Université de Lille, Sciences Humaines et Sociales.

${ }^{1}$ Claude Vigée, Mon heure sur la terre. Poésies complètes, 1936-2008, préface de Michèle Finck, introduction d'Anne Mounic, Paris, Galaade Éditions, 2008, p. 499.

${ }^{2}$ Claude Vigée, La lune d'hiver. Récit - Journal - Essai, Paris, Champion, 2002, p. 113.

${ }^{3}$ Pour reprendre la belle formule de Sylvie Parizet, dans Là où chante la lumière obscure... Hommage à Claude Vigée, sous la direction de S. Parizet, Paris, Éditions du Cerf, 2011, p. 293.
} 
Claude, tu portes la prophétie et le serment d'Isaïe $(49,18)$ dans ton nom même, Vigée, haï ani, «moi vivant» [...] dans le haï ani, il y a une revendication de vivre contre les drogués de la mise à mort et de la haine de la vie, et ainsi, invisiblement, c'est une parabole du poème [...] Et c'est aussi, si je peux dire, l'auto-simultanéité des moments de la vie qui est inscrite dans le présent de haï ani. $^{4}$

Ainsi le poète, dans la lignée de Jacob, entamait-il une lutte sans relâche contre Esaü, ce frère jumeau, marcheur vers la mort.

Le 26 octobre 1942, alors que l'étau se resserre autour de lui, Claude Vigée franchit avec sa mère la frontière des Pyrénées et tous deux s'embarquent le 19 novembre, à Lisbonne, sur le Serpa Pinto faisant route vers New York. Dans le Nouveau Monde, où il retrouve Évy, sa cousine germaine qu'il épouse en 1947, et où naissent leurs deux enfants, Claudine et Daniel; il entame une brillante carrière à l'université de Brandeis où il dirige le département des langues romanes. Il n'en vit pas moins cet exil comme une véritable traversée du désert, se sent déplacé, « out of place »" Dans l'improbable clarté de la «lune d'hiver », afin d'échapper à l'agonie et à l'aphasie, il rédige La corne du grand pardon, Les poèmes de l'été indien et une partie des textes de Canan d'exil et s'affirme bientôt comme l'un des plus grands poètes français contemporains. Puis vient le «retournement / simple et miraculeux de l'exil en présence $»^{6}$ lorsque, le 30 septembre 1960, veille de Kippour, la famille arrive en Israël où Claude Vigée poursuit son enseignement à l'université hébraïque de Jérusalem et où il apprend l'hébreu aux côtés de son fils Daniel. Cette installation, vécue comme un « retour» qui ne se traduira pas pour autant en terme «d'enracinement», inaugure une période d'intense créativité dans une double extase des sens et de la parole :

Le cœur qui sut attendre au plus noir de l'exil

Et survivre à minuit, par la grâce de l'agonie

Connaîtra la nouvelle joie qui germait dans le temps. ${ }^{7}$

Dans l'éblouissement de la lumière de Judée, sur cette terre promise qui l'attend autant qu'il l'a attendue (comment ne pas songer à

\footnotetext{
${ }^{4}$ Henri Meschonnic, « Avec Claude Vigée, c'est l'oreille qui voit », dans Claude Vigée, Danser vers l'abîme, Paris, Parole et Silence, 2004, avant-propos.

${ }^{5}$ Claude Vigée, La lune d'hiver, op. cit., p. 432.

${ }^{6}$ Claude Vigée, Mon heure sur la terre, op. cit., p. 724.

${ }^{7}$ « Le poème du retour », dans Mon heure sur la terre, ibid., p. 379.
} 
Jacob et Rachel ?), le poème d'exil s'inverse en un long Poème $d u$ retour. Il fait l'expérience de la réciprocité du désir, de l'éclosion de l'être, d'une nouvelle naissance et d'une nouvelle alliance partagée avec le peuple et la femme aimée dans les " Noces d'Amnon et de Tamar », chant jubilatoire qui se dresse comme une colonne de lumière et de sensualité $^{8}$. Les années passent entrecoupées du va-et-vient entre Jérusalem, l'Alsace et Paris où le couple s'installe définitivement en 2001 en raison de l'état de santé d'Évy, qui décède en 2007. «Attendsmoi dans la nuit / où tu sommeilles en paix », dit le poème lu le 22 janvier $2007^{9}$ dans le cimetière de Bischwiller, où Claude Vigée repose désormais depuis le 6 octobre dernier à ses côtés et auprès de Daniel, disparu trop tôt, ultime épreuve, terrible, qui fit de lui «l'orphelin » de son fils.

Dans sa belle préface à Mon heure sur la terre, Michèle Finck évoque la «double paternité spirituelle, biblique et musicale : celle de Jacob et celle de Mozart », qui fait de la poésie de Vigée une œuvre bâtie « sur un jeu de contrepoint entre la lutte et la grâce ${ }^{10}$. La parole dansante du poète, qui alterne avec la claudication, se déploie, entre « extase et errance», dans un perpétuel va-et-vient entre la source, le silence primordial de l'Aleph, antérieur à toute parole proférée, et l'instant où celle-ci jaillit, mêlant, dans ce qu'il nomme son "judan », l'horizontalité de la prose à la verticalité du poème ${ }^{11}$. Maître incontesté de la langue française, Claude Vigée sera également l'un des artisans du renouveau de la poésie alsacienne, de ce dialecte enfoui au fond de luimême qui ressurgit en 1982 sur une terrasse de Jérusalem où il compose en quelques jours son admirable - et ô combien provocateur " requiem alsacien », Schwàrzi sengessle flàckere ém Wénd [Les orties noires flambent dans le vent] qui se termine sur l'assomption de la langue refoulée.

Juif rescapé qui voit avec angoisse ses étudiants israéliens partir pour le front, le poète est tout sauf un adepte de la contemplation et de l'art pour l'art. Il fut sa vie durant un lutteur, un résistant, comme en témoigne son auvre, tout aussi remarquable, d'essayiste et de

\footnotetext{
${ }^{8}$ Ibid., p. 390-398.

${ }^{9}$ Ibid., p. 779.

${ }^{10}$ Sur l'héritage de Mozart, voir également le bel article de Michèle Finck: « Épiphanies musicales dans la poésie de Claude Vigée », dans Là où chante la lumière obscure..., op. cit.

${ }^{11}$ Voir à ce propos Claude Vigée, L'extase et l'errance, Paris, Grasset, 1982.
} 
comparatiste $^{12}$. La force et la légitimité de sa critique tient à son double héritage, à l'intimité qui le lie à l'objet de sa critique (l'anthropologie binaire et la perversion dualiste prééminentes dans la pensée et dans la littérature occidentales) et à cette étrangeté qui lui permet de maintenir ses distances : «Rien de plus contraire à l'essence judaïque », dit-il, « que ces conceptions dualistes auxquelles notre civilisation s'est vouée à en mourir ! ${ }^{13}$. À l'instar d'Henri Meschonnic, son ami et complice, il puise dans l'héritage juif son pouvoir de résistance à la tentation nihiliste de l'Occident et sa capacité de subversion. Sa critique littéraire, à redécouvrir, est pour le lecteur la source d'un plaisir infini ressenti dans un rapport nouveau au texte et éveille en lui un désir et un véritable appétit de littérature.

Avec la mort de Claude Vigée, nous perdons un ami, un être délicieux, chaleureux, volontiers espiègle, qui avait fondé sa relation aux autres sur l'écoute. Dans ce lieu accueillant qu'était son appartement parisien, c'était un pur ravissement que de l'entendre évoquer avec humour «la verte enfance du monde» dans cette petite communauté juive de la campagne alsacienne, dominée par la présence du grand-père Léopold $^{14}$, ou de relire en sa compagnie le Cantique des Cantiques qui, disait-il, porte « dans sa version originale [...] la marque d'une jeunesse éternelle ${ }^{15}$ dont il avait su garder le secret. Il nous laisse pour héritage son œuvre, comme une boussole afin de nous orienter, peut-être, en cette période d'obscurité et de désenchantement persistant du monde qui s'accompagnent d'une tentation au repli et d'une résurgence de la barbarie dont il a toujours entrevu la possibilité :

Si mes poèmes, mes récits, mes témoignages vont servir à quelque chose, n'estce pas à nous frayer un sentier vers le lieu de la confiance première ? Et puis à forer, par un rebondissement inouï, l'autre chemin, contraire mais parallèle ; un chemin qui serait le frère jumeau du premier. Celui de l'ouverture au temps et à l'espace habités de ce monde, au sein duquel nous nous enfonçons comme un fleuve s'écoule vers l'océan, en y répandant au passage la semence de ses

\footnotetext{
${ }^{12}$ Cf. l'anthologie d'essais sélectionnés par Vigée lui-même, Rêver d'écrire le temps, de la forme à l'informe, Paris, Orizons, 2011.

${ }^{13}$ Claude Vigée, "Civilisation française et génie hébraïque », dans Pentecôte à Bethléem : choix d'essais 1960-1987, Paris, Parole et Silence, 2006, p. 83.

${ }^{14}$ Enfance sur laquelle Claude Vigée ne cessait de faire retour, merveilleusement décrite dans les deux tomes du Panier de houblon, parus chez Lattès en 1994 et 1995, et dont le premier tome, « La verte enfance du monde », valut à son auteur le Prix Wizo.

${ }^{15}$ Claude Vigée - Victor Malka, Le puits d'eaux vives. Entretiens sur les Cinq Rouleaux de la Bible, Paris, Albin Michel, 1993, p. 26.
} 
grandes eaux qui étincellent dans le soir montant, et fécondent librement le ventre de la terre. ${ }^{16}$

Au lendemain de Souccoth 5781, c'est avec émotion et une infinie gratitude que nous prêtons l'oreille au murmure de ses poèmes entrelacés et que nous risquons, en dépit de la fragilité de la condition humaine, ce pas dans l'ouvert auquel nous convie sa parole hospitalière :

\section{VOCATION DU POÈTE}

Toujours reverdissant sur leurs hautes ramures

depuis près de quatre-vingts ans,

tous nos poèmes entrelacés rêvent d'être le murmure

d'une vaste souccah au clair de lune qui danse

la hora d'automne en plein vent :

pour le plaisir des vieux et des jeunes enfants

sa grande porte bat entre terre et planètes,

de jour comme de nuit ouverte à tout vivant!

veille de Souccoth 5767

5 octobre $2006^{17}$

\footnotetext{
${ }^{16}$ Claude Vigée, Dans le silence de l'Aleph, Paris, Albin Michel, 1992, p. 13.

${ }^{17}$ Claude Vigée, Mon heure sur la terre, op. cit., p. 775.
} 
Dans le port d'Ascalon

Les bergers nus lessivent

Leurs brebis dans la mer :

Les filles aux pieds bruns

Font claquer leurs sandales

Dans la coupole d'air

Sur chaque dalle blanche.

\author{
L'oil du soleil élève \\ À hauteur d'univers \\ Jérusalem future \\ Qu'inaugure l'éclair \\ De la neige d'été.
}

Mon heure sur la terre, op. cit., p. 421 